\title{
ARTE Y CIENCIA: COMPLEMENTARIEDAD MANIFIESTA ANTE HALLAZGOS ANATÓMICOS INÉDITOS EN LA ESCULTURA DE LA CABEZA DECAPITADA DE SAN JUAN BAUTISTA, DE GASPAR NÚÑEZ DELGADO
}

\author{
ART AND SCIENCE: MANIFEST COMPLEMENTARITY \\ TO REPRESENT UNPUBLISHED ANATOMICAL \\ FINDINGS IN BEHEADED SCULPTURE OF SAINT JOHN \\ THE BAPTIST, BY GASPAR NÚÑEZ DELGADO
}

\author{
JuAN DíAZ OLleR* \\ juan.diaz.oller@gmail.com
}

\begin{abstract}
La simbiosis entre el Arte y la Ciencia ha sido una constante en la Humanidad, pero alcanza su máxima expresión a partir del Renacimiento. Sin embargo, la aplicabilidad evidente de los conocimientos anatómicos a la realización de obras de arte ha sido poco descrita. Nuestro objetivo ha sido realizar un estudio iconográfico/anatómico en la escultura de la cabeza decapitada de San Juan Bautista, de Gaspar Núñez Delgado, en el Museo de Bellas Artes de Sevilla -aprovechando el realismo del autor protobarroco- y descifrar los detalles expresivos y anatómicos que se encuentran en ella, revelando la existencia de una tumoración cutánea facial y otra tiroidea no descritas hasta el momento.

Palabras clave: Anatomía Artística. Iconografía. San Juan Bautista. Decapitación. Escultura.
\end{abstract}

* Este artículo es un resumen del trabajo que presenté en la asignatura de Iconografía, del Grado de $\mathrm{H}^{\circ}$ del Arte.

Agradezco al Dr. Carlos Javier Catalina Herrera (Prof. Titular de Anatomía de la Facultad de Medicina de la Univ. de Sevilla), al Dr. José Cantillana Martínez (Prof. Titular de Cirugía de la Facultad de Medicina de la Facultad de Medicina de la Univ. de Sevilla, al Dr. Gerardo García León, Asesor Técnico de la Secretaría General de Cultura de la Junta de Andalucía, al Dr. Antonio Luna Fantony, al Dr. Moisés El Adel del Fresno y a la Dra. $\mathrm{M}^{\mathrm{a}}$ del Valme Muñoz Rubio, las sugerencias y facilidades para obtener el material gráfico. 
The symbiosis between Arts and Science has been a constant in Humanity, but it is not until the Renaissance that reaches its height. However, the apparent applicability of anatomical knowledge to the completion of works of art has been poorly described. Our objective was to perform an iconographic and anatomical study of Saint John the Baptist beheaded sculpture, by Gaspar Núñez Delgado, located at the Fine Arts Museum in Seville -using the early baroque realism of the author-and thus, we have figured out the expressive and anatomical details shown in it, revealing the existence of a facial skin and other thyroid tumor far undescribed.

Key words: Artistic Anatomy. Iconography. Saint John the Baptist. Decapitation. Sculpture.

\section{INTRODUCCIÓN}

La conjunción entre Arte y Ciencia no es una novedad del Renacimiento, pero tiene sus antecedentes próximos de apogeo entre los artistas del siglo XV y XVI, con la traslación de los conocimientos científicos a las llamadas Bellas Artes. Leonardo da Vinci, Miguel Ángel, Alberto Durero, junto a sus dotes creacionistas, no se contentaron con aplicar los conocimientos de la anatomía griegos, árabes o medievales a sus obras, sino que investigaron por su cuenta sobre el cuerpo humano. Andrea Vesalio, con su obra De humanis corporis fabrica reúne ciencia y humanismo. Se basó en la observación directa sobre la disección de cadáveres, aprovechando la habilitación de dichas prácticas por el Papa Sixto IV, (en el siglo XV eran solo toleradas en ocasiones) ${ }^{1,2}$. Anatomistas y artistas, muchas veces conformados en una misma persona -mediante la disección de los cadáveres y su aplicación a la escultura y pintura del cuerpo humano- buscan la verdad anatómica amparados en el rigor científico y la estética, expresándolos en el naturalismo y en el realismo barroco.

En España, la Escuela Sevillana de finales del Renacimiento y del ProtoBarroco, cuenta con un escultor fundacional de relevancia: Gaspar Núñez Delgado. Palomero Páramo $(1983)^{3}$ lo describe como “... entre el manierismo de corte idealista, ... y su incipiente realismo...donde exhibe una fuerte tensión dramática en algunos de sus cristos de marfil y la crudeza áspera de la muerte en sus cabezas degolladas".

${ }^{1}$ GARCÍA GUERRERO, Marcos: "La revolución de la anatomía en el Renacimiento". Rev Cient Soc Esp Enferm Neurol, 35,2012, pp. 25-27

${ }^{2}$ CASTIGLIONI, Arturo: "Andreas Vesalius. Professor at the Medical School of Padua”. Bull NY Acad Med, 19(11), 1943, pp. 766-777

${ }^{3}$ PALOMERO PÁRAMO, Jesús Miguel: El retablo sevillano del Renacimiento, Sevilla. Publicaciones de la Excma. Diputación Provincial de Sevilla, Sección Arte, Serie $1^{\mathrm{a}}, \mathrm{n}^{\mathrm{o}} 18,1983$, pp. $386-390$ 
Entre su obra como barrista, destaca la Inmaculada que hizo para la parroquia de San Andrés, de Sevilla, imágenes de Ecce $\mathrm{Homo}^{4}$ y especialmente la $\mathrm{Ca}$ beza de San Juan Bautista de la que vamos a tratar.

A tenor de lo publicado por Martín González 5 , Ravé Prieto 6 y Palomero Páramo et al. (1992) ${ }^{7}$ sabemos que, al final del periodo medieval, la temática de la decapitación de los Santos en general (San Pablo, siempre representado mayor y calvo o con los cabellos canos, San Juan Bautista, joven, Santa Justa, San Dionisio...) estuvo muy extendida. Particularmente lo fue la de San Juan Bautista, y las ciudades en las que se daba culto a las reliquias de San Juan: Amiens, Roma...difundieron muchas imágenes que consolidaron su culto.

Como cirujano-anatomista y estudiante de Historia del Arte me propuse realizar un estudio iconográfico-anatómico de la escultura sobre la cabeza decapitada de San Juan Bautista, de Gaspar Núñez Delgado, en el Museo de Bellas Artes de Sevilla, centrado especialmente en la sección del cuello, para contribuir con sus hallazgos a la investigación iconográfica sobre la obra citada y a la exaltación de su autor.

\section{MATERIAL Y MÉTODO EMPLEADO}

Material

Escultura de la Cabeza de San Juan Bautista, de Gaspar Núñez Delgado (1591), en el Museo de Bellas Artes de Sevilla.

${ }^{4}$ LUNA MORENO, Luis: “Gaspar Núñez Delgado y la escultura del barro cocido en Sevilla". Laboratorio de Arte, 21, 2008-2009, pp. 379-394

${ }^{5}$ MARTÍN GONZÁLEZ, Juan José: "Cabezas de Santos degollados en la escultura española”. Goya. Revista de Arte, 16, 1957, pp. 210-213

6 "Podría explicarse la reiteración en la Historia del Arte, y su simbología, como representación de la vida del Precursor y precedente del martirio por excelencia, el sacrificio de Cristo. Por ello, aparece también como alegoría Eucarística. A la estética del dolor de raíz gótica se añade, posteriormente a este emblema del sacrificio, la experimentación y el análisis propios de la modernidad, que fue tratado con renovado interés en el Renacimiento y en el Barroco". RAVÉ PRIETO, Juan Luis. "La cabeza de San Juan Bautista. Notas sobre los cambios de uso en el patrimonio mueble" en V Jornadas sobre Historia de Marchena. El Patrimonio y su conservación. Marchena (Sevilla). Excmo. Ayuntamiento de Marchena, 2000, pp. 113-123

7 PALOMERO PÁRAMO, Jesús Miguel, QUILES GARCÍA, Fernando, VALDIVIESO GONZÁLEZ, Enrique: "Cabeza degollada de San Juan Bautista". En: Obras Maestras del Museo de Bellas Artes de Sevilla: siglos XV-XVIII: (pequeño y mediano formato ). Sevilla, Fundación Fondo de Cultura de Sevilla (FOCUS). 1992, pp. 150-151. 
La consulta bibliográfica se ha realizado utilizando el Catálogo FAMA de la Biblioteca de la Universidad de Sevilla (U.S.) ${ }^{8}$, para la obtención de la mayoría de los documentos, y sobre los estudios anatómicos de cabeza y cuello en afamados textos anatómicos profesionales y de amplia consulta: Testut-Jacob ${ }^{9}$, Rohen-Yokochi-Lütjen ${ }^{10}$, Chung Wan-Kim ${ }^{11}$. También se ha utilizado un Programa Digital Anatómico ${ }^{12}$ del Departamento de Anatomía de la Facultad de Medicina de la U.S.

Nos han sido cedidas imágenes de Resonancia Magnética (RM), anónimas, de la Clínica Radiológica SERCOSA (Jaén), por el Dr. Antonio Luna Fantony.

Hemos recabado Información de Documentos en Internet, a través del buscador GOOGLE, y Base de Datos específicas Médicas internacionales y del CSIC: Medline, Índice Médico Español (IME), y Sumarios ISOC - Ciencias Sociales y Humanidades.

\section{Métodos}

Obtención de permisos ante la Dirección el Museo de Bellas Artes de Sevilla para la realización de las fotografías, que han sido realizadas sin flash (con trípode) y sin retirar la urna protectora de la escultura por si se producía algún daño al ser de terracota.

Se trata de un estudio descriptivo de la escultura referida, comparativo con imágenes anatómicas de cortes transversales del cuello a nivel de las vértebras cervicales $6^{\mathrm{a}}(\mathrm{C}-6)$ y $7^{\mathrm{a}}$ (C-7), de láminas de los textos anatómicos referidos, de cadáver congelado y con imágenes al mismo nivel obtenidas por Tomografía Axial Computarizada (TAC), y RM.

\section{RESULTADOS}

La citada Cabeza, es una donación de la Colección González-Nandín y Paul realizada al Museo de Bellas Artes de Sevilla en 1980 (Figura 1). Tiene $20 \mathrm{~cm}$.

8 "Catálogo FAMA". Biblioteca de la Universidad de Sevilla. Actualizada el 28 Mar 2014. Citada el 24 de Julio de 2014. Disponible en: http://fama.us.es/

9 TESTUT, Leo, JACOB, O: Tratado de Anatomía Topográfica. (Ed. 8). Barcelona. Salvat Editores S.A., 1975, t. I, pp. 619-752

${ }^{10}$ ROHEN, Johannes Wolfgang, YOKOCHI Chihiro, LÜTJEN-DRECOLL Elke. Atlas fotográfico de Anatomía humana. ( $4^{\mathrm{a}}$ Ed.). Madrid. Harcourt Brace de España S.A., 1998, pp. 150-181

${ }^{11}$ CHUNG HAN, Man, WAN KIM, Chu: Cortes anatómicos relacionados con TC y RM. (3 ${ }^{\text {a }}$ Ed.). Marban Libros S.L.; 1998

12 NIEDER, Gary L., NAGY, Frank: Beyond Vesalius. The visible human proyect. National Library of Medicine[CD-ROM]. Wrigh State University. School of Medicine. Dayton (Ohio). mFactory inc.; 1995-1997 
de altura y está firmada y fechada en 1591, en la cara posterior (acostumbraba a firmar bastantes de sus obras), modelada en barro, policromada de coloración pálido-cianótica. Tiene rasgos de un difunto joven, delgado, con el cuello en su aspecto externo de la cara anterior, de esternocleidomastoideos resaltados, así como un cartílago tiroides prominente. Rizos del cabello alborotado y encrespado sobre la frente formando un mechón. Bucles ensortijados, y vello facial abundante y asímismo crespo, con el mechón bipartito del mentón. Leve giro de la cabeza hacia la derecha, y boca entreabierta con labios carnosos, mostrando dientes bien esculpidos y algo desgastados.

El dorso de la pirámide nasal achaflanada, con discreta epistaxis que muestra unos leves hilos de sangre emergiendo de las fosas nasales (apreciándose todo el vestíbulo) que surcan, sin coagular aún, los ángulos nasogenianos. Una lesión nodular epidérmica, con un punto central, de unos cuatro milímetros, aparece en la mejilla derecha (Figura 2).

Párpados entreabiertos, relajados, que dejan entrever unos ojos con pupila midriática pero aún brillantes, y globos oculares prominentes.

En lo referente a la sección del cuello -sección discretamente oblicua hacia la derecha, tomando parte de la fosa supraclavicular- se aprecia que está realizada por debajo del cartílago tiroides, posiblemente a nivel del $2^{\circ}$ o tercer anillo traqueal y a la altura del espacio intervertebral cervical $6^{\circ}-7^{\circ}$ o $7^{\circ}$ cervical- $1^{\mathrm{a}}$ dorsal, dadas las relaciones anatómicas que se aprecian en la escultura, comparativamente con una RM a ese nivel (Figura 3). Hay un pequeño colgajo cutáneo en la región derecha (Figura 4).

En la porción anterior y en la línea media, a la altura de la prominencia del cartílago tiroideo y a unos $5 \mathrm{~cm}$. de ella, una oquedad de estructura tubular, de unos $25 \mathrm{~mm}$. de luz: la tráquea. Inmediatamente debajo de ella, otra estructura sólida, de aspecto óseo, discretamente cóncava, lisa, de aspecto poroso sin fragmentar, de unos $30 \mathrm{~mm}$., por la que discurren algunas gotas de sangre reciente en declive. Es la cara articular inferior del cuerpo de una de las últimas vértebras cervicales. No se visualiza el disco intervertebral (Figuras 4 y 5).

El arco vertebral no se ve bien en esta proyección, pero sí se aprecia la médula espinal, por delante de la apófisis espinosa prominente descrita.

Parece visualizarse el esófago como una lámina mal definida, entre la tráquea y el cuerpo vertebral.

Llama la atención una estructura irregular a la derecha de la tráquea, bien definida, de distinta coloración (más amarillenta), de unos $25 \mathrm{~mm}$. de eje mayor antero-posterior, simétrica con otra a su izquierda pero de menor tamaño (15 mm.) , discontinua pero en relación con otra horizontal por encima. Corresponde a la glándula tiroides con su istmo central y ambos lóbulos, con un desarrollo mayor e irregular en el derecho y más teniendo en cuenta la discreta oblicuidad hacia la derecha de la sección (Figuras 4 y 5). 
Las yugulares internas se visualizan colapsadas, apareciendo en el lugar anatómico habitual -detrás de los lóbulos tiroideos- sin apreciarse excesivo sangrado. Asímismo, las carótidas, se intuyen redondeadas y pequeñas por la retracción, en su lugar habitual por detrás de las yugulares internas y de los lóbulos tiroideos, externas a ellos.

Los nervios no se visualizan claramente en la escultura y, la estructura encontrada en la zona del paquete yugulo-carotídeo es probablemente el nervio vago.

Las estructuras redondeadas y enrojecidas alrededor de la tráquea y cuerpo vertebral son los músculos, definidos en su mayor parte. En la cara anterior, los esternocleidomastoideos con tres haces musculares desarrollados, a ambos lados y por delante de la tráquea, casi en solución de continuidad con el istmo tiroideo, aunque independientes, que tienen repercusión por su volumen haciendo prominencia por debajo de la piel, especialmente en este modelo de complexión robusta. Inmediatamente por detrás y por dentro, los músculos esternocleidohioideos, omohioideos, esternotiroideo y tirohioideo. Le siguen los músculos escalenos. En profundidad y posteriores, próximos a la apófisis espinosa, los músculos complexo mayor y semiespinosos del cuello, y ya en la zona más posterior los trapecios. Los músculos subescapular y supraespinoso no se visualizan, aunque pueden intuirse los músculos largos de la cabeza y cuello (Figura 5).

\section{DISCUSIÓN}

Al no encontrar antecedentes bibliográficos que refieran comentarios anatómicos al respecto, ni en esculturas de cabezas otros de tipo iconográfico-anatómico, la discusión se va a limitar a la comparación de la escultura con la descripción de los signos de la muerte y alteraciones fisiopatológicas, si las hubiere, en la cara y cuello - descritas en las monografías clásicas ${ }^{13},{ }^{14}-$, con modelos de las láminas esquemáticas de los atlas de anatomía, las secciones en cadáver y sus correspondencias radiológicas en cuanto a la TAC y RM de los manuales consultados referidos en la metodología ,así como en las RM anónimas cedidas por el Servicio de Radiología SERCOSA (Jaén) (Figura 3) y el Programa Digital

${ }^{13}$ ROYO-VILLANOVA Y MORALES, Ricardo: "Estudio de los procedimientos modernos para la comprobación de la muerte real". Anales de la Real Academia Nacional de Medicina. Real Academia Nacional de Medicina. 1948; Tomo LXV, cuaderno cuarto, pp. 440-445. Citada el 24 Jul 2014. Disponible en: http://books.google.es/books?id=3LPFHs. $\mathrm{SxV} 4 \mathrm{C} \& \mathrm{pg}=\mathrm{PA} 444 \& \operatorname{lpg}=\mathrm{PA} 444 \& \mathrm{dq}=$ facies + cadav $\% \mathrm{C} 3 \% \mathrm{~A} 9$ ricas\&source $=$ bl\&ots $=\_3 \mathrm{xT}$ MWXYCq\&sig=Xo6P9PBO68Aj4xbochhgTQS2XyY\&hl=es\&sa=X\&ei=bLhOU6yIPM SX1AXetoHACQ\&redir_esc $=\mathrm{y} \# \mathrm{v}=$ onepage $\& \mathrm{q}=$ facies $\% 20 \mathrm{cadav} \% \mathrm{C} 3 \% \mathrm{~A} 9 \mathrm{ricas} \& \mathrm{f}=$ false

${ }^{14}$ TRUJILlO NIETO, Gil Ambrosio: Medicina Forense. México. Ciencia y cultura latinoamericana; 1998 
de imágenes Beyond Vesalius cedido por el Departamento de Anatomía de la Facultad de Medicina de la U.S. ${ }^{15}$.

A primera vista, la expresión facial, que sin ser aún de tipo cadavérico con las mejillas y párpados entreabiertos, relajados, que dejan entrever unos globos oculares prominentes (¿protruyentes por exoftalmos?) de pupila midriática, pero aún brillantes, presumen una muerte reciente que, posiblemente esperada, es recibida sin crispación.

En la facies, entre los rasgos más llamativos desde el punto de vista anatómico, una correcta coloración pálido-cianótica del cadáver, sin acentuar lo violáceo en su justo medio ya que se supone bastante exangüe. Es una fiel demostración de las dotes del maestro para modelar, y en la que el naturalismo de la imagen no va en detrimento de su belleza plástica. El perfecto modelado, que acentúa los rasgos patéticos, nos acerca un correcto estudio anatómico de la cabeza de un difunto, joven y delgado, con un cuello de esternocleidomastoideos resaltados, así como un cartílago tiroides prominente que acentúa su masculinidad. Todo lo referido, asociado al tratamiento de los rizos del cabello ${ }^{16}$. La estructura capilar, ensortijada, y vello facial abundante y crespo, con el mechón bipartito del mentón nos lo sitúan en primera fila de los protobarrocos, acrecentado con el naturalismo del leve giro de la cabeza hacia la derecha, y el realismo de la boca entreabierta, posiblemente por la relajación en los primeros momentos de los músculos maseteros que hacen que caiga la mandíbula, mostrando dientes bien esculpidos y algo desgastados pero sin alteraciones morfológicas (no habitual en la época), que parece más una idealización dulcificada como paréntesis del realismo que expresa. Labios carnosos de una persona joven, relajados al igual que la lengua, en la ausencia todavía de facies cadavérica antes de su contracción en las horas posteriores por el rigor mortis, exhala el último hálito de vida.

Y abundando en el realismo, el dorso de la pirámide nasal achaflanada posiblemente por traumatismo previo muy reciente ya que no se aprecian equimosis, intencionado o por la caída al suelo de la cabeza, aunque también podría tratarse de fractura antigua de los huesos nasales, dificultando la expresión de nariz afilada hipocrática. La leve epistaxis, acentúa el dramatismo.

Una pequeña tumoración nodular en la mejilla derecha, de unos $4 \mathrm{~mm}$, con caracteres de benignidad en lo que se representa, tiene el aspecto de un quiste de inclusión epidérmica con un poro central, y pone el contrapunto singular.

En cuanto a la sección del cuello, sin lesión ósea, suponemos que el artista nos la ha querido mostrar como realizada por un afilado y contundente elemento cortante,

${ }^{15}$ NIEDER, Gary L., NAGY, Frank: Beyond Vesalius...op. cit

16 "... alborotado y encrespado sobre la frente formando el típico mechón que en el siglo XVII explotarán, entre otros Martínez Montañés y Juan de Mesa”. PALOMERO PÁRAMO, Jesús Miguel, et al.: "Cabeza degollada de San Juan...”, op. cit. p. 47 
si bien realizado en al menos dos golpes, como lo demuestra el pequeño colgajo cutáneo en la región derecha que induce a precisar la dirección de izquierda a derecha.

Llama la atención el diámetro traqueal de unos $25 \mathrm{~mm}$. de luz, superior al máximo de $18 \mathrm{~mm}$ de las descripciones anatómicas en el adulto varón ${ }^{17}$, a pesar de la relajación de la musculatura de la misma post-mortem y del tamaño de la cabeza algo superior al patrón real, realzando el dramatismo. El cuerpo de la vértebra cervical visualizada - muy posiblemente la $7^{\mathrm{a}}$ por la prominencia de la apófisis espinosa- tiene un tamaño de unos $30 \mathrm{~mm}$, superior también al tamaño habitual $^{18}$, y en relación con el tamaño de la tráquea a ese nivel, quizás por el mismo motivo. No se aprecia el arco vertebral con el canal medular, oculto por la musculatura de la zona. La no visualización de la luz esofágica puede estar en relación con el aplastamiento/retracción del traumatismo de la sección.

Un hallazgo destacable es el tamaño asimétrico e irregular del lóbulo tiroideo derecho, con aumento importante del mismo con respecto al izquierdo que es de tamaño normal a ese nivel así como el istmo tiroideo. Esto hace pensar en que el modelo padecía de un bocio de predominio derecho (¿en relación con el exoftalmos descrito?, posiblemente una tumoración hiperfuncionante ¿maligna al no ser uniforme, redondeada y de distinta coloración?).

Los paquetes vasculares venosos profundos (yugulares internas) se visualizan colapsados por la contusión, apareciendo en el lugar anatómico habitual -detrás de los lóbulos tiroideos- sin apreciarse excesivo sangrado, lo que explicaría la cierta coloración cianótica y escasa palidez. Los nervios (el identificado como probable nervio vago por la situación con respecto a los vasos formando el paquete vasculonervioso), al ser de una coloración amarillenta similar a la grasa, y delgados, no se visualizan claramente en la escultura.

Los músculos/paquetes musculares están bien conformados, resaltando especialmente los esternocleidomastoideos (entre los enumerados en los resultados), trifasciculados e hipertrofiados de acuerdo a la complexión atlética (por la conformación del cuello) que debía tener, así como los trapecios y espinosos/semiespinosos.

Todo ello, en una difícil mezcla de realismo y naturalismo que conjuga los signos clásicos de la muerte natural o accidental, bien documentada en la Medicina Legal y Forense de los autores Royo-Villanova ${ }^{19}$, Trujillo Nieto ${ }^{20}$ y Gisbert

${ }^{17}$ TESTUT, Leo, JACOB, O.: Tratado de Anatomía... op.cit. p. 669

${ }^{18}$ BAZALDÚA CRUZ, Juan José, GONZÁLEZ LARIOS, Amalia, GÓMEZ SÁNCHEZ, Arnulfo, VILLARREAL SILVA, Eliud Enrique, VELÁZQUEZ GAUNA, Sergio Everardo, et al. :"Morphometric study of cervical vertebrae C3-C7 in a population from Northeastern Mexico". Int J Morphol, 29 (2), 2011, pp. 325-330

${ }^{19}$ ROYO-VILLANOVA Y MORALES, Ricardo: Estudio de los procedimientos modernos ...op. cit.

${ }^{20}$ TRUJILlO NIETO, Gil Ambrosio: Medicina Forense. Op.cit 
Calabuig ${ }^{21}$, con este tipo peculiar por decapitación con descripción incompleta aislada $^{22}$, pero supuestas por lo narrado y lo sabido por la fisiopatología.

La apreciación de Romero Torres en la similitud comparativa con modelos romanos, es compartida ${ }^{23}$.

En conclusión, la decapitación es un tema tratado ampliamente en el arte de los siglos XVI al XVII, y cómo no en la escultura, siguiéndolo en la Cabeza de San Juan Bautista, realizada por Gaspar Núñez Delgado, no habiéndose encontrado ningún estudio anatómico sobre la misma u otras similares. La conjunción de Cirujanos, anatomista e Historiadores del Arte, ha hecho posible este original estudio. De los resultados obtenidos y su discusión, se deduce que la obra está realizada de acuerdo a un conocimiento y habilidad artística en consonancia con la realidad, los conocimientos de los tratados anatómicos -como los de Vesalio, entre otros, y a los que pudo tener acceso $^{24}$ - y muy probablemente tomando como modelos a cadáveres ad hoc, sin trabas ya de tipo religioso ${ }^{25}$. Los elementos elaborados en la escultura de Gaspar Núñez Delgado, siguen un patrón anatómico con un figurativismo realista, según se deduce de las comparaciones con las láminas anatómicas esquemáticas, de los cortes anatómicos sobre cadáver congelado, y sobre los estudios radiológicos de TAC y RM, llegando a plasmar en la terracota la alteración anatómica que presentaría el cadáver en cuanto a la pequeña tumoración de la mejilla, posiblemente un quiste de inclusión epidérmica con el mínimo detalle y en lo que se refiere a otra alteración anatómica como es la existencia de una tumoración en el lóbulo derecho del tiroides, posiblemente hiperfuncionante, con caracteres morfológicos sugestivos de malignidad. La obra estudiada es merecedora de exaltación por su fidelidad, y pienso que este estudio iconopatológico saca a la luz detalles ocultos hasta la actualidad.

Fecha de recepción: 10 de septiembre de 2014

Fecha de aceptación: 28 de noviembre de 2014

${ }^{21}$ GISBERT CALABUIG, Juan Antonio. "Lesiones por arma blanca”. En: Gisbert Calabuig JA, Villanueva Cañadas E. Barcelona. Medicina Legal y Toxicología. (6 $\left.{ }^{\mathrm{a}} \mathrm{ed}.\right)$. Barcelona, 2004, pp. 383-393.

${ }^{22}$ RODRÍGUEZ HIDALGO, Beatriz, MARTÍNEZ TÉLLEZ, Inmaculada, BOTELLA LÓPEZ María del Carmen: Suicidio por decapitación con sierra mecánica. Cuad med forense. 2011, 17, pp. 39-42. Citada el 24 Jul 2014. En: http://scielo.isciii.es/scielo. php?pid=S1135-76062011000100007\&script $=$ sci_arttext\#f3

23 “ La composición y la expresión de la cabeza reflejan la influencia de los modelos escultóricos romanos difundidos en el siglo XVI a través de los grabados o dibujos, como la cabeza de Alejandro moribundo y el grupo de Laocoonte". ROMERO TORRES, José Luis: "Cabeza de San Juan Bautista". En: Velázquez y Sevilla: Catálogo. Sevilla. Consejería de Cultura. Junta de Andalucía, 1999, pp. 70-71

${ }^{24}$ CASTIGLIONI, Arturo: Andreas Vesalius... op. cit

${ }^{25}$ GARCÍA GUERRERO, Marcos: La revolución de la anatomía... op. cit. 


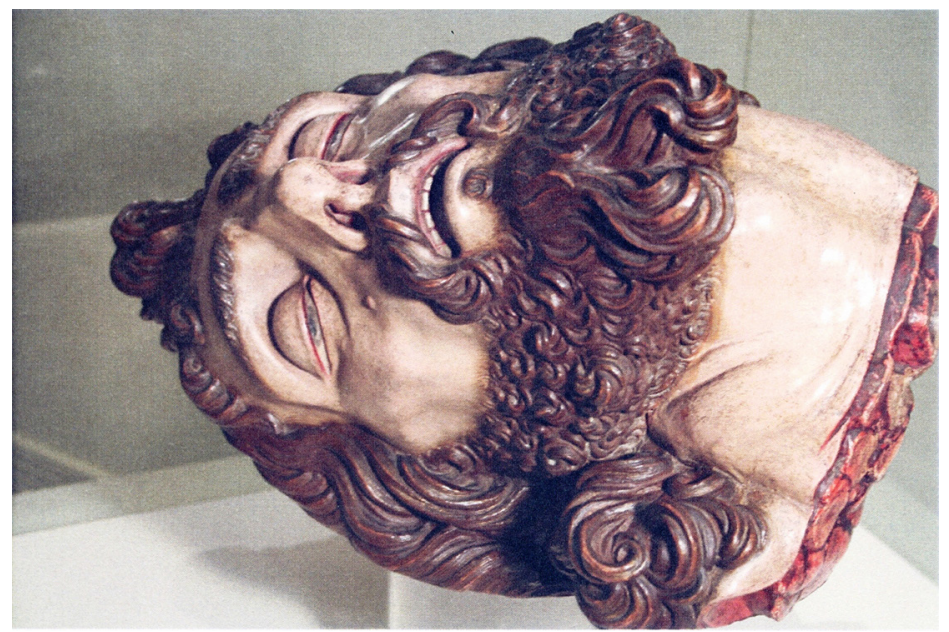

Figura 1. Cabeza de San Juan Bautista. Gaspar Núñez Delgado. (1591). (Museo de Bellas Artes de Sevilla). Detalle de las fosas nasales, nódulo en mejilla derecha, dentadura, cartílago tiroideo, parte de la fosa supraclavicular derecha y de la sección cutánea del cuello con el pequeño colgajo.

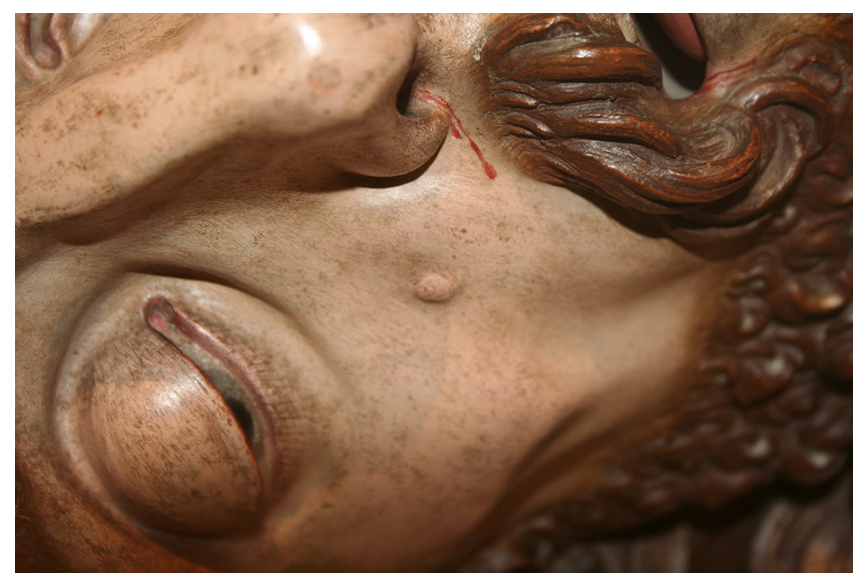

Figura 2. Cabeza de San Juan Bautista. Gaspar Núñez Delgado (1591). (Museo de Bellas Artes de Sevilla). Detalles: Aplastamiento nasal. Nódulo en mejilla. Epistaxis. Lengua. Ojos. 


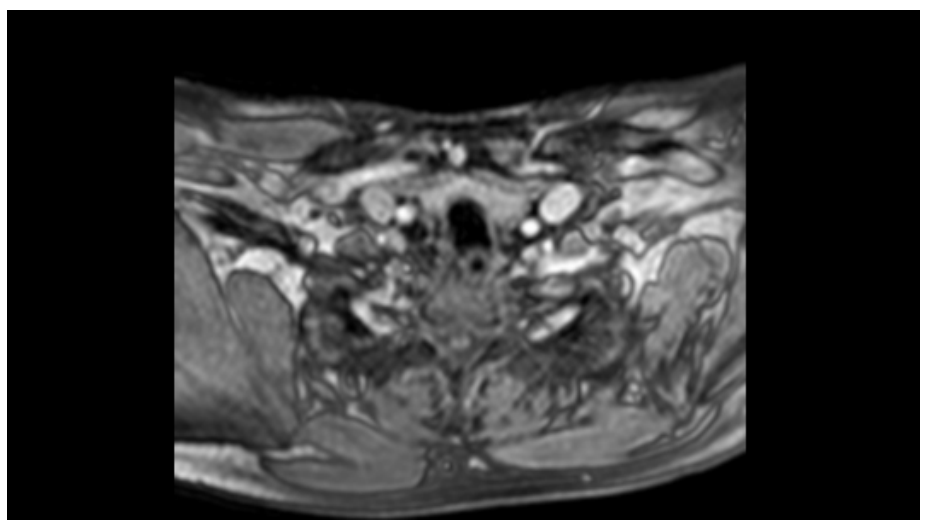

Figura 3. RM de cuello. Sección transversal $7^{\mathrm{a}}$ vértebra cervical. Cedida por la Clínica Sercosa, de Jaén. Anónima.

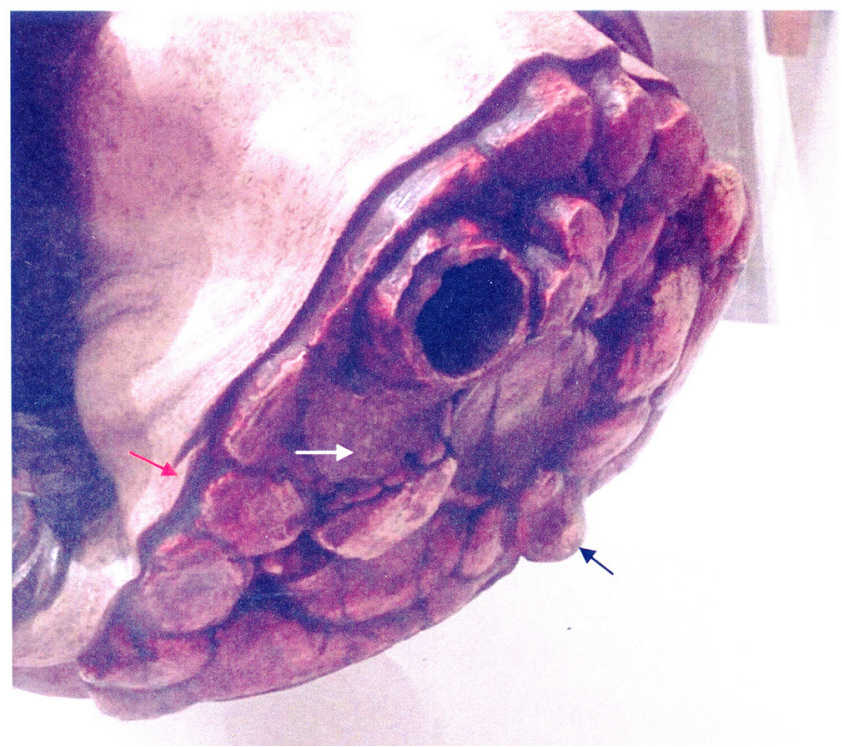

Figura 4. Sección cervical de la escultura de la Cabeza de San Juan Bautista. Gaspar Núñez Delgado (1591).

(Museo de Bellas Artes de Sevilla). Detalle.

Se aprecia pequeño abultamiento en borde inferior tratándose de la apófisis espinosa de la $7^{\mathrm{a}}$ vértebra cervical (flecha negra), y el pequeño colgajo cutáneo (flecha roja), así como la tumoración tiroidea (flecha blanca). 


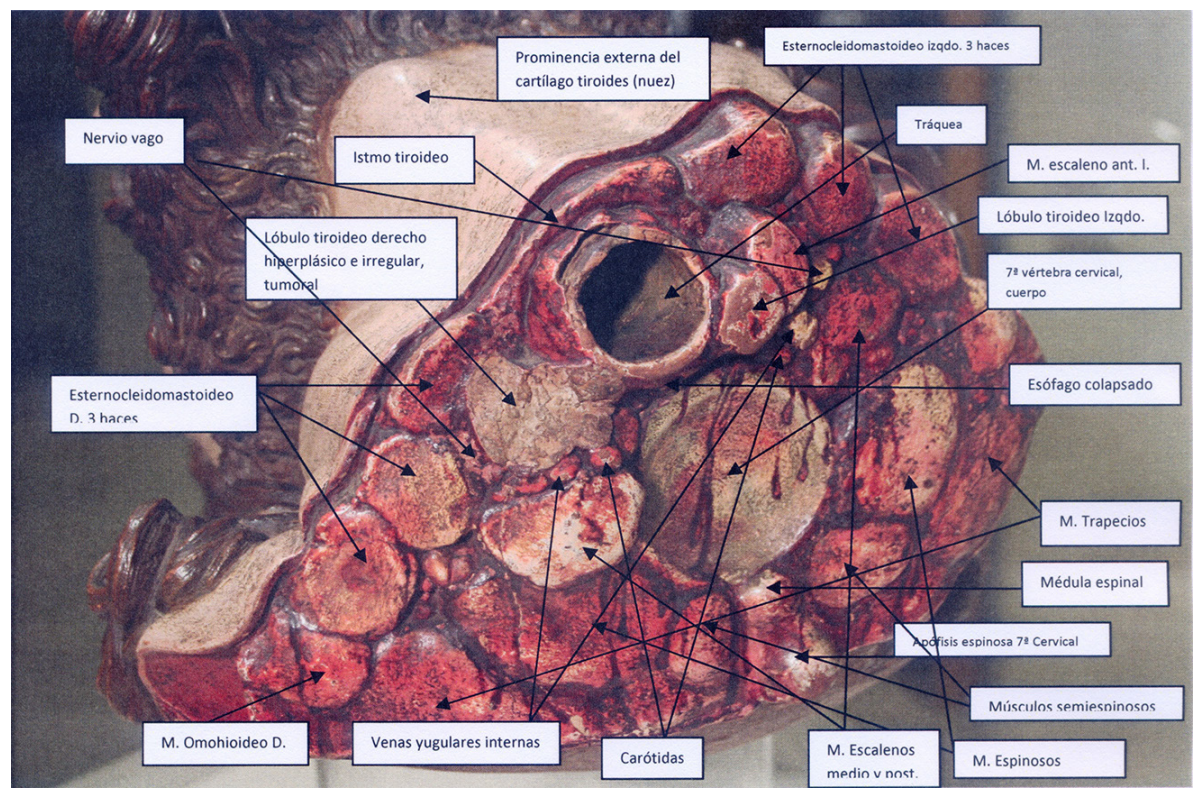

Figura 5. Sección cervical de la escultura de la Cabeza de San Juan Bautista. Gaspar Núñez Delgado (1591). (Museo de Bellas Artes de Sevilla). Definición de las principales estructuras. 